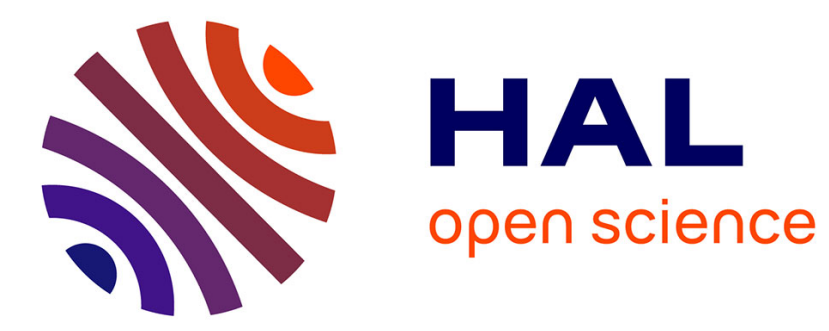

\title{
Comparative analysis of pesticide action plans in five European countries
}

\author{
Marc M. Barzman, Silke Dachbrodt-Saaydeh
}

\section{To cite this version:}

Marc M. Barzman, Silke Dachbrodt-Saaydeh. Comparative analysis of pesticide action plans in five European countries. Pest Management Science, 2011, 67 (12), pp.1481 - 1485. 10.1002/ps.2283 . hal-02645292

\section{HAL Id: hal-02645292 \\ https://hal.inrae.fr/hal-02645292}

Submitted on 29 May 2020

HAL is a multi-disciplinary open access archive for the deposit and dissemination of scientific research documents, whether they are published or not. The documents may come from teaching and research institutions in France or abroad, or from public or private research centers.
L'archive ouverte pluridisciplinaire HAL, est destinée au dépôt et à la diffusion de documents scientifiques de niveau recherche, publiés ou non, émanant des établissements d'enseignement et de recherche français ou étrangers, des laboratoires publics ou privés. 


\title{
Comparative analysis of pesticide action plans in five European countries
}

\author{
Marco Barzman $^{\mathrm{a} *}$ and Silke Dachbrodt-Saaydeh ${ }^{\mathrm{b}}$
}

\begin{abstract}
BACKGROUND: Denmark, Germany, the Netherlands, France and the United Kingdom have launched national initiatives to reduce pesticide use or risk. Faced with multiple environmental, social and economic constraints such as ensuring the competiveness of European agriculture, the various programmes address goal setting, stakeholder involvement and the role of research and extension in different ways. These diverse experiences offer valuable insights for the development of national action plans required by new European legislation on pesticides.
\end{abstract}

RESULTS: The general trend is to move away from volume or use reduction targets towards reductions in risks and impact. All programmes studied pay attention to involving a wide range of stakeholders in the policy-making process to ensure buy-in. Research and extension services are important players that help to define appropriate goals and improve implementation. Collective approaches to implementation appear to be more effective than the classical linear research-extension-farmer model.

CONCLUSION: No matter the approach adopted in fine, member states can gain much from sharing their diverse experience through comparisons such as this study and via international policy seminars which serve as valuable forums for exchange.

(c) 2011 Society of Chemical Industry

Keywords: pesticide policy; ENDURE; Europe; target; stakeholders; research; extension

\section{INTRODUCTION}

During the last decade, a number of European countries have launched national initiatives to reduce pesticide use or risk. These experiences offer valuable insights for the development of national action plans required by new European legislation on pesticides. This paper looks at how Denmark, Germany, the Netherlands, France and the United Kingdom - faced with multiple environmental, social and economic constraints such as ensuring the competiveness of European agriculture - have addressed goal setting, stakeholder involvement and the role of research and extension in their programmes.

\section{GOAL SETTING}

Programmes on pesticide use and risk reduction are all associated with a goal formulated in terms of volume, frequency of use or risk and impact. However, there is considerable variation in the way member states have chosen to measure progress. Some have adopted quantified and time-bound targets, while others have not. The general trend has been to move away from volume reduction goals towards reduction in use, environmental impact and risk.

\subsection{Volume}

The simplest target is probably reduction in pesticide volume consumption. Along with emission reduction targets, the Netherlands, which in the 1980s had the highest pesticide use per area, used such a target. Its Multiyear Crop Protection Plan included a target of $50 \%$ overall volume reduction by 2000 relative to the 1984-1988 reference period. The target was quickly reached without adversely affecting yields, in large part resulting from an $85 \%$ volume reduction in nematicide soil disinfectants. Here, one obvious criticism of volume reduction targets is that they do not take into account the replacement of lower-dose pesticides with newer and more potent active ingredients. In fact, in its subsequent 2001-2010 programme, the Netherlands switched to an impact reduction target.

\subsection{Treatment frequency}

To measure progress in use reduction and avoid the pitfalls of simply monitoring volumes, Denmark developed the treatment frequency index (TFI), which is the theoretical number of pesticide treatments per hectare, based on standard dose rates of active ingredients and the amount of pesticides sold yearly. A TFI of 1 is equivalent to one full dosage treatment applied to agricultural land. In three successive Danish pesticide action plans, the TFI was used to evaluate progress. ${ }^{1}$ In the first plan, this indicator was useful in showing that, in spite of achieving a $50 \%$ reduction in

\footnotetext{
* Correspondence to: Marco Barzman, Institut National de la Recherche Agronomique, Unité Eco-Innov, Avenue Lucien Brétignières, 78850 Thiverval-Grignon, France.E-mail:Marco.Barzman@grignon.inra.fr

a Institut National de la Recherche Agronomique, Unité Eco-Innov, Thiverval-Grignon, France

b Julius Kühn Institut, Federal Research Centre for Cultivated Plants, Kleinmachnow, Germany
} 
volume over a 10 year period, the TFI was only reduced by the equivalent of $2 \%$ of a full-dose treatment down to a TFI of 2.45 by 1997, a recognition that prompted actions specifically designed to optimise use beyond mere volume reduction. The TFI was used as an overall target in the second and third plans, successfully reached in the former (TFI 2.0 by 2000) and not in the latter (TFI 1.7 by 2009). ${ }^{2}$

In France, treatment frequency is now receiving all the attention. As a result of a national consultation, the 'Grenelle de I'Environnement', the French Minister of Agriculture announced in 2009 an objective of ' $50 \%$ reduction in pesticide use by 2018, if possible'.3 The objective was translated into a $50 \%$ reduction in treatment frequency. Because sales figures were available only for active ingredients and not for products, a more complex calculation than the Danish TFI was necessary to estimate treatment frequencies per crop.

Naturally, there are drawbacks to relying on treatment frequency. In Denmark, for example, the International Biocontrol Manufacturers' Association (IBMA) argued that TFI trends are not associated with progress on the use of the least toxic products, as it does not discriminate between products. The IBMA argues in favour of agri-environmental indicators and considers that for many years the Danish policy missed an opportunity to promote biological control agents. ${ }^{4}$ In isolation, reduction in treatment frequency is not sufficient to reach conclusions regarding trends in environmental and health risks, even though a correlation is commonly assumed. However, a study conducted in Denmark did show that lower dosages were associated with increased onfarm biodiversity, including number of weed and bird species and abundance of beneficial insects. ${ }^{5}$ Another concern is that the use of dosages lower than officially registered dose rates may accelerate acquired resistance of pests to pesticides and reduce efficacy of control. With respect to wheat diseases at least, the Danish experience shows that lower doses will have no such adverse effects when decided upon on the basis of sound and extensive agronomic and biological information. ${ }^{6}$

\subsection{Risk and impact}

Adopting a target on risk and impact would resolve such shortcomings, but measuring them is complex and requires detailed data on the various ecological compartments. In France, a 2006-2009 action plan required the development of an environmental risk indicator as a major monitoring tool, but the development of environmental impact targets, indicators and a monitoring system were postponed until 2012.

In contrast, the 2009 German National Action Plan on Sustainable Use of Plant Protection Products has taken up the challenge. It is based on a target of $25 \%$ risk reduction by 2020 relative to the 1996-2005 average. The synoptic assessment model for pesticides, known as SYNOPS, is the main tool with which risk is assessed. ${ }^{7}$ It is a model used to analyse the risk potential of plant protection strategies, taking into account active substance toxicity in the context of the landscapes. It considers the exposition of aquatic and terrestrial ecosystems by drift, run-off and drainage using geo-referenced databases for land use, soil conditions, climate data and pesticide use. The adoption of a risk reduction target was made possible by a substantial investment in research and by making pesticide use data available from a periodic and random sample of representative farms in all German regions.

Interestingly, Denmark, in its new and comprehensive 2009-2015 'green growth' policy, has set aside its TFI and is instead focusing its target on environmental impact. It has adopted a target equivalent to TFI 1.4, as measured by the new 'pesticide impact index' to be reached by 2013. It takes into account pesticide use, the extent of non-sprayed areas and the pesticide burden on health and the environment.

Similarly, the Netherlands also moved towards environmental impact. Its 2003 National Agreement on Crop Protection aims at a $95 \%$ reduction in the environmental impact by 2010 relative to 1998 , as measured by the ratio of predicted exposure concentration on water organisms to the no-effect concentration. In this respect it is worth mentioning PRIBEL (Pesticide Risk Indicator for BELgium), a broad risk indicator combining environmental impacts with operator and food consumer exposure. ${ }^{8}$ It is used against the ambitious Belgian goal of $50 \%$ risk reduction by 2012 relative to 2001.

\subsection{No target}

In the five countries above, an overall quantitative and timebound target was adopted as a national rallying point around which to build multifaceted initiatives. The benefits of having such targets is obvious; in the words of a Danish government official: 'Setting quantitative use reduction targets will concretise, support and allow for monitoring progress towards the objective of encouraging low-input or pesticide-free cultivation'. ${ }^{9}$ In this regard, the UK Pesticides Strategy adopts a different approach. In the United Kingdom there is no single indicator used against a single national goal. Rather, there are six separate action plan groups - on biodiversity, water, availability of products and techniques, amenity use, amateur use and health - each with its own respective indicators, desired strategic outcome and headline and core indicators. In addition to indicators, it is the task of each action plan group to develop targets. ${ }^{10}$ The groups were set up in 2006 - except for the human health action plan group which was initiated in 2008. To date, except for the biodiversity group, which translated the UK Government's commitment to 'reversing the long-term decline in the numbers of farmland birds by 2020' (Pesticides in the United Kingdom) into the goal of 'halting the loss of biodiversity caused by plant protection products', the other groups have not adopted specific and quantitative targets. ${ }^{11}$ One positive aspect of the lack of a time-bound quantified target is increased communications attention to a broader set of more specific and subtle indicators that may carry more information for the wider public. A similar strategy is found in other countries such as Hungary, whose current plan does not include the adoption of a single target. ${ }^{12}$

\section{STAKEHOLDER INVOLVEMENT}

Successful involvement of stakeholders in policy development helps to ensure a high level of buy-in. This is particularly true for pesticide policies, which concern the entire agri-food system.

The well-known 'polder model' refers to the Dutch know-how in coordinating a diversity of stakeholders around large initiatives. The 2003 National Agreement signalled a new collaboration among a remarkably diverse set of stakeholders around the 2010 goal. ${ }^{13}$ The signatories included the ministries of agriculture and of the environment, farmer organisations, the pesticide industry and distributors, water boards and water companies, input suppliers and NGOs. The agreement is often hailed as a success in concerted action, but the NGO most competent on pesticide issues, 'Natuur \& Milieu', left the agreement mid-course. The walk-out can be traced to the government's reintroduction of previously banned 
substances in parallel with that NGO's continued legal efforts to ban pesticides, both of which eroded mutual trust. ${ }^{2}$

Denmark initially embarked on its action plans via binding legislation driven by government. Achieving further progress in the second action plan meant enlisting voluntary farmers. For that, the Bichel Committee, a new organisational structure with experts from farming, NGO, industry, research and government sectors, was set up. The committee was very active and engaged in a joint assessment of goals and means. ${ }^{8}$ This multistakeholder process is widely recognised as a major ingredient for the subsequent success of the action plans. More recently, the 'green growth' economic policy was translated into crop protection subpolicies via a closed process among five ministries. To avoid farmer rejection of compulsory measures, the government covers up to $80 \%$ of costs incurred by farmers for advisory support on integrated pest management.

Germany adopted a new approach based on multistakeholder consultations in 2002 and 2003, resulting in the development of the first reduction programme. In the course of negotiations, the NGO PAN Germany did not fully support the final plan owing to the absence of a quantitative reduction target. A stakeholder conference in 2009 to adapt the 2008 National Action Plan on Sustainable Use of Plant Protection Products to the new EU Directive 2009/128/EC was more successful in gaining wider buy-in. The reason was that the new plan included a $25 \%$ risk reduction target and strove to reduce exceedances of maximum residue levels to stricter than EU standards at least on national food products. Thematic working groups with representatives of national and Länder agencies and grower organisations are currently finalising the plan.

France has a history of non-constructive conflict around the pesticide question. In 2007, however, the government-launched 'Grenelle de l'Environnement' signalled the involvement of a wide diversity of stakeholders in genuine dialogue and co-construction of solutions. The Ecophyto 2018 plan was co-developed by representatives of government, research, farming, training and extension, industry and input suppliers and 'France Nature Environnement' and 'Mouvement pour le Droit et le Respect des Générations Futures' - the two French environmental NGOs most involved in the pesticide question. These stakeholders are now formally included in a national committee that meets 3 times a year jointly to monitor and evaluate the plan and propose adjustments.

In the United Kingdom, a variety of stakeholders have been involved in the above-mentioned initiatives for a long time. The Pesticide Forum is a multistakeholder group that was set up in 1996. It brings together representatives of environmental, conservation and consumer interests, as well as from farming and the pesticide industry, and oversees and monitors the six action plans and advises government. There are other initiatives where stakeholders independent from government are given significant responsibilities. In 2001, for example, as an alternative to a proposed pesticide tax, the government accepted a proposal from the pesticide industry and farmer organisations to develop and lead the Voluntary Initiative, which oversees training and sprayer testing and encourages farmers to produce crop protection management plans. Another example is the handing-over of the administration of Environmental Stewardship in England, a major agri-environmental scheme, to Natural England, a nondepartmental public body. The government, prompted by the new EU legislation, recently conducted a wide stakeholder consultation on their pesticide policy sent to more than 900 consultees. Based on the responses (306), it decided in favour of minor adjustments of the current policy in response to two planned consultations on more specific questions. ${ }^{14}$

\section{RESEARCH AND EXTENSION}

The classical diffusion model of research and extension - where knowledge is generated by research, then handed over to advisory services which then 'transfer' it to farmers - is increasingly being replaced by more collective and participatory approaches. The mainstreaming of practices contributing to a reduction in pesticide use or risks is an innovation process where new knowledge, tools and services need to be generated and shared among multiple actors. Research and extension are key players in this process. All national plans studied are associated with substantial research and extension efforts dedicated to the national goal.

\subsection{Research}

In general, in the countries studied, research efforts focus on disease forecasting and decision support, the development of alternative control methods such as mechanical weed control, innovative application techniques, control of diseases using resistant varieties, biological control of pests in greenhouses and organic agriculture. The German research programme also includes long-term experiments on integrated plant protection. In Denmark the bulk of research and extension efforts associated with the Danish plans have focused on the optimisation of existing systems, much of which has involved optimising the use of pesticides, including the potential for using reduced dosages. In the United Kingdom, research efforts appear to be separate from the Pesticides Strategy. The main relevant research priorities are nevertheless identified in the plan. These include assessing and managing risks in support of regulatory work, sustainable crop protection practices and ways to protect biodiversity in support of policy, alternative plant protection technologies and integrated crop management to reduce reliance on chemical products, pesticide resistance and support to monitoring and enforcement activity. ${ }^{10}$

Research conducted prior to adopting a plan helps to define targets and means to reach those targets. In Denmark, for example, the 1.7 TFI target was adopted on the basis of research showing that this was the most that could be aimed for without causing a major economic burden to farmers. ${ }^{15}$ In France, a preliminary research programme laid the groundwork for the implementation of the Ecophyto 2018 plan. It showed that a $20 \%$ TFI reduction was achievable without either major changes or economic loss. To attain the $50 \%$ reduction target, however, the study showed that radical transformations are required. Whereas the Danish research emphasised economic optimisation of existing systems, including optimised use of pesticides and reduced dosages, the French Ecophyto research programme is developing the means of attaining the target. Researchers hypothesise that systemic changes at the level of farming systems and food supply chain are needed to achieve the ambitious goal. Diversification of crop rotations and cropping system redesign are now at the centre of debates.

\subsection{Extension}

Denmark has an extensive farmer-funded advisory service. It has been very innovative in its efforts to support farmers and advisers, for example running 'experience groups' designed to generate 
collective learning processes. These groups are composed of one adviser and 5-8 farmers who meet regularly during a growing season. Today, there are 428 such registered groups covering the majority of farms. ${ }^{16}$

In the Netherlands, an original organisational set-up was also promoted as part of the 2001-2010 plan. 'Telen met Toekomst' (or 'Farming with Future') is a programme that set up 35 regional networks where farmers, researchers, advisors, input suppliers and water board representatives form new coalitions and collectively devise solutions on specific bottlenecks in the sustainability of crop protection. The technologies and strategies that are supported by these networks are then disseminated to the entire agricultural sector. ${ }^{17}$

In the United Kingdom, much of the effort to promote more sustainable farming practices, including crop protection, comes from non-governmental sectors. The Voluntary Initiative (VI) and Linking Environment and Farming (LEAF) are two notable examples. The VI now enjoys the support of government and of major farmer organisations. It has become an important part in the UK Pesticides Strategy and represents the largest national effort to reduce impacts on water and biodiversity. LEAF is an independent charitable organisation that works as an intermediary between farmers, retailers and consumers. It runs a farmer education programme, including an innovative selfassessing audit, and it oversees an environmentally responsible label - the LEAF marque - which facilitates access to a number of UK supermarkets.

France and Germany are both set to invest significantly in innovative extension efforts that will provide a large role to on-farm experimentation, demonstration and data collection. The French plan calls for the establishment of 50 experimental sites and 800 participating farms to generate knowledge and learning on highperformance cropping systems based on long and diversified rotations in annual systems and suites of agronomic practices adapted to low pesticide input in all systems. The benefits of such systemic changes only become apparent over the longer term. That is why on-farm and on-station trials are planned to be conducted for durations of up to 5 and 10 years respectively. In this research and extension effort, advisors are encouraged to take farmer knowledge into account and to engage farmers in the process of problem formulation as well as problem-solving.

The German plan acknowledges the importance of close collaboration between independent state advisory services and farmers transferring integrated pest management and innovative technologies into practice via 30 demonstration farms. Pesticide use data, collected via a network of 100 reference farms, are used to calculate the annual treatment index and estimate the regional 'necessary minimum', which represents the amount of pesticide needed for efficient crop production. It serves as a communication tool to support farmer self-assessments.

\section{CONCLUSION}

European member states adopt a variety of approaches to facing the challenge of reducing the risks and impacts of pesticide use on human health and the environment while maintaining the competiveness of European agriculture. Many are adopting a single objectively verifiable target, which appears to be useful in mobilising a diversity of stakeholders towards a common goal. However, the UK experience indicates that, given sufficient attention, a strong multistakeholder process can also be achieved in the absence of a single goal. The nature of the targets seems to be evolving away from reductions in volume or use, which are relatively easy to measure, towards reductions in risks and impact, which are more difficult to assess and require more technical and human resources. In all cases, stakeholder involvement in the policy-making process needs to be taken seriously to avoid rejection. The process, which builds on an agreement towards a common goal, goes beyond mere consultation - it involves trust-building and long-term involvement. This is particularly important with respect to NGO involvement, which is a more recent development. Efforts should also be made to involve important players in the agri-food system, such as retailers, to ensure that market-driven strategies are compatible with both the renewed health and environmental demands - which can translate into zero-residue-level requirements on fresh produce - and the pest management constraints faced by farmers. Research and advisory systems play a key role towards achieving the set goals. Initial research is helpful in developing appropriate policy goals during the policy-making phase. During implementation, the focus of the research can range from optimisation of pesticide use to redesigning agricultural systems according to national goals. Past successful experiences indicate that collective approaches where research, extension services, farmers and other stakeholders join forces are more conducive to innovation. In the future, all national plans will be scrutinised against and aligned with the upcoming reform of the Common Agricultural Policy, which is likely to contain 'greening' requirements for direct subsidies. It will be important to find a balance between voluntary uptake of environmentally friendly risk reduction technologies on the one hand and inclusion of formerly subsidised agri-environmental measures converted into cross-compliance greening requirements on the other hand.

No matter the approach adopted in fine, member states can obviously gain much from sharing their diverse experience. They can build on successful experiences of other member states, as, for example, in France with the novel involvement of various stakeholders in the process leading to the Ecophyto 2018 plan, or in several countries with the adoption of the treatment frequency index as a measurement for pesticide use. In this regard, meetings such as the 'EU Expert Meeting' held in Berlin in 2007, 'Sustainable Agriculture and Pesticides' in Paris in 2008 or 'Sustainable Use of Pesticides and IPM in East-Central Europe and the Baltics' in Poland in 2011 serve as valuable forums for exchange.

\section{ACKNOWLEDGEMENTS}

This paper was produced as a task of the ENDURE network www.endure-network.eu. The authors thank all ENDURE partners who contributed to this paper. They also thank E Soubeyran, W Zornbach, J Molnar, A Dixon and G Smagghe for their useful input.

\section{REFERENCES}

1 Joergensen L, Jensen JE, Melander B, Kudsk P, Clark B, Ferguson A, et al, Possible reasons for differences in pesticide use in wheat in some EU countries participating in ENDURE, in Integrated Pest Management in Europe. INRA (2010).

2 Lamine C, Societal Assessment of Current and Novel Low Input Crop Protection Strategies. [Online]. ENDURE deliverable DR 3.11 (2009). Available: www.endure-network.eu/endure_publications/ deliverables [29 July 2011].

3 Ecophyto R\&D: Which Options to Reduce Pesticide Use? [Online]. INRA (2010). Available: http://www.international.inra.fr/the_institute/ advanced_studies/ecophyto_r_d [29 July 2011].

4 Blum BJ, Agri-environmental indicators for biological control and IPM, in OECD Agri-environmental Indicators: Lessons 
Learned and Future Directions. [Online]. OECD (2010). Available: www.oecd.org/dataoecd/55/49/44795866.pdf [29 July 2011].

5 Esbjerg P and Petersen BS, Effect of reduced pesticide use on flora and fauna in agricultural fields. Pestic Res 58:165 (2003).

6 Joergensen $\mathrm{L}$ and Thygesen $\mathrm{K}$, Fungicide resistance and its impact on recommendations to farmers - experiences from Denmark, in Fungicide Resistance: Are We Winning the Battle but Losing the War? University of Edinburgh, Scotland, UK. ed. by Bryson RJ. Association of Applied Biologists, Wellesbourne, UK, pp. 65-70 (2006).

7 Strassemeyer J and Gutsche V, The approach of the German pesticide risk indicator SYNOPS in frame of the National Action Plan for Sustainable Use of Pesticides. in OECD Agrienvironmental Indicators: Lessons Learned and Future Directions. [Online]. OECD (2010). Available: http://www.oecd.org/dataoecd/ 32/16/44806454.pdf [29 July 2011].

8 van Bol V, Policies regarding pesticide and biocide risk management in Belgium, in EU Expert Meeting on 'National Plans and Programmes for the Reduction of Risks Associated with the Use of Plant Protection Products', Berlin, 13-14 March 2007. EU (2007). Available: http://nap.jki.bund.de/index.php?menuid=52\&downloadid $=183$ \&reporeid=0 [29 July 2011].

9 Gravesen L, Pesticides Plan 2004-2009 for Reducing Pesticide Consumption and its Impact on the Environment, in EU Expert Meeting on 'National Plans and Programmes for the Reduction of Risks Associated with the Use of Plant Protection Products', Berlin, 13-14 March 2007. EU (2007). Available: http://nap. jki.bund.de/index.php?menuid $=52 \&$ downloadid $=183 \&$ reporeid $=$ 0 [29 July 2011].

10 Stark L, UK Pesticide National Action Plans, in EU Expert Meeting on 'National Plans and Programmes for the Reduction of Risks
Associated with the Use of Plant Protection Products', Berlin, 13-14 March 2007. EU (2007). Available: http://nap.jki.bund.de/index.php? menuid $=52 \&$ downloadid $=183 \&$ reporeid $=0$ [29 July 2011].

11 Pesticides in the UK - the 2008 report on the impacts and sustainable use of pesticides. Pesticides Forum (2008).

12 Molnar J, Talk given during session 'Addressing IPM in National Action Plans' at the ENDURE Conference 'Integrated Pest Management in Europe', November 2010, Paris, France (2010).

13 Beerling EAM and De Buck AJ, Implementation of biological control in glasshouse horticulture in the Netherlands. Second International Symposium on Biological control of $\bullet$ Arthropods. USDA Forest Service Publication FHTET-2005-08, Davos, Switzerland (2005).

14 Consultation on the Implementation of EU Pesticides Legislation; Summary and Government Response. [Online]. DEFRA (2010). Available: http://webarchive.nationalarchives.gov.uk/201103181 31226/ http:/defra.gov.uk/corporate/consult/pesticides/index.htm [29 July 2011].

15 Ørum JE, Jørgensen LN and Jensen PK, Farm-level economic consequences of a reduced use of pesticides in Danish Agriculture. Farm Manag 11:495-507 (2003).

16 Thostrup PR and Petersen PH, Using Experience Groups to Share Knowledge and Reduce Pesticide Use. [Online]. ENDURE (2009). Available: www.endure-network.eu/endure_publications/ endure_publications2 [29 July 2011].

17 Brinks $\mathrm{H}$ and De Kool S, Farming with future: implementation of sustainable agriculture through the network of stakeholders, in Changing European Farming Systems for a Better Future, ed. by Langeveld $\mathrm{H}$ and Röling N. Wageningen Academic Publishers, The Netherlands, pp. 159-163 (2006). 